\title{
Correction to: Assessment of a virtual reality temporal bone surgical simulator: a national face and content validity study
}

Evan C. Compton ${ }^{1}$, Sumit K. Agrawal ${ }^{2,3}$, Hanif M. Ladak ${ }^{2,3,7}$, Sonny Chan ${ }^{4}$, Monica Hoy ${ }^{1}$, Steven C. Nakoneshny ${ }^{5}$, Lauren Siegel ${ }^{2}$, Joseph C. Dort ${ }^{1,5^{*}+}$ and Justin T. Lui ${ }^{6+}$

\section{Correction to: J Otolaryngol Head Neck Surg https://doi.org/10.1186/s40463-020-00411-y}

Following publication of the original article [1], the authors identified incorrect ordering and incorrect files being used for Figs. 1, 2 and 3.

The correct Figs. 1, 2 and 3 have been included in this Correction, and the original article has been corrected.

\begin{abstract}
Author details
${ }^{1}$ Section of Otolaryngology-Head and Neck Surgery, Department of Surgery, Cumming School of Medicine, University of Calgary, Calgary, Alberta, Canada. ${ }^{2}$ Department of Otolaryngology-Head and Neck Surgery, Western University, London, Ontario, Canada. ${ }^{3}$ Department of Electrical and Computer Engineering, Western University, London, Ontario, Canada. ${ }^{4}$ Department of Computer Sciences, University of Calgary, Calgary, Alberta, Canada. ${ }^{5}$ Ohlson Research Initiative, Arnie Charbonneau Cancer Institute, Cumming School of Medicine, University of Calgary, 3280 Hospital Dr. NW, Calgary, AB T2N 4Z6, Canada. ${ }^{6}$ Department of Otolaryngology-Head and Neck Surgery, University of Toronto, Toronto, Ontario, Canada. 'Department of Medical Biophysics, Western University, London, Ontario, Canada.
\end{abstract}

Published online: 22 April 2020

\section{Reference}

1. Compton EC, Agrawal SK, Ladak HM, Chan S, Hoy M, Nakoneshny SC, Siegel

L, Dort JC, Lui JT. Assessment of a virtual reality temporal bone surgical simulator: a national face and content validity study. J Otolaryngol Head Neck Surg. 2020;49:17 https://doi.org/10.1186/s40463-020-00411-y.

The original article can be found online at https://doi.org/10.1186/s40463020-00411-y.

* Correspondence: jdort@ucalgary.ca

† Joseph C. Dort and Justin T. Lui are co-senior authors

${ }^{1}$ Section of Otolaryngology-Head and Neck Surgery, Department of Surgery, Cumming School of Medicine, University of Calgary, Calgary, Alberta, Canada ${ }^{5}$ Ohlson Research Initiative, Arnie Charbonneau Cancer Institute, Cumming School of Medicine, University of Calgary, 3280 Hospital Dr. NW, Calgary, AB T2N 4Z6, Canada

Full list of author information is available at the end of the article

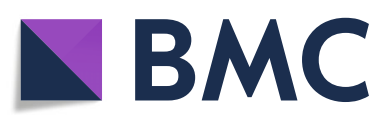

(c) The Author(s). 2020 Open Access This article is licensed under a Creative Commons Attribution 4.0 International License, which permits use, sharing, adaptation, distribution and reproduction in any medium or format, as long as you give appropriate credit to the original author(s) and the source, provide a link to the Creative Commons licence, and indicate if changes were made. The images or other third party material in this article are included in the article's Creative Commons licence, unless indicated otherwise in a credit line to the material. If material is not included in the article's Creative Commons licence and your intended use is not permitted by statutory regulation or exceeds the permitted use, you will need to obtain permission directly from the copyright holder. To view a copy of this licence, visit http://creativecommons.org/licenses/by/4.0/ The Creative Commons Public Domain Dedication waiver (http://creativecommons.org/publicdomain/zero/1.0/) applies to the data made available in this article, unless otherwise stated in a credit line to the data. 

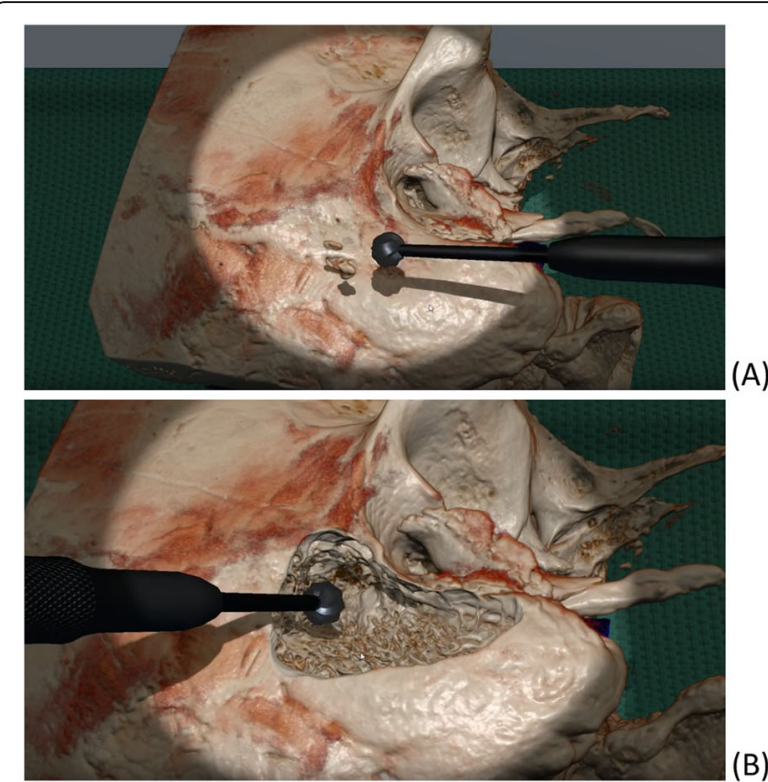

(B)

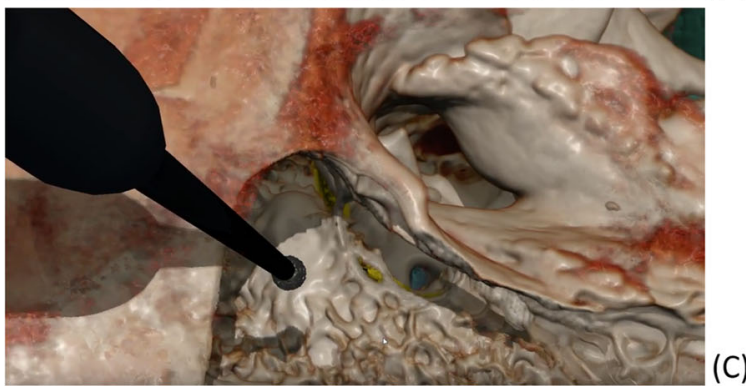

Fig. 1 Screenshots of CardinalSim at varying stages of tympanotomy dissection. a Pre-dissection virtual reality segmented human cadaveric temporal bone. $\mathbf{b}$ Mid-dissection exposure of lateral semicircular canal completed with cutting burr drill. c Facial recess approach to round window completed with diamond burr drill, short process of incus and facial nerve (yellow) identified

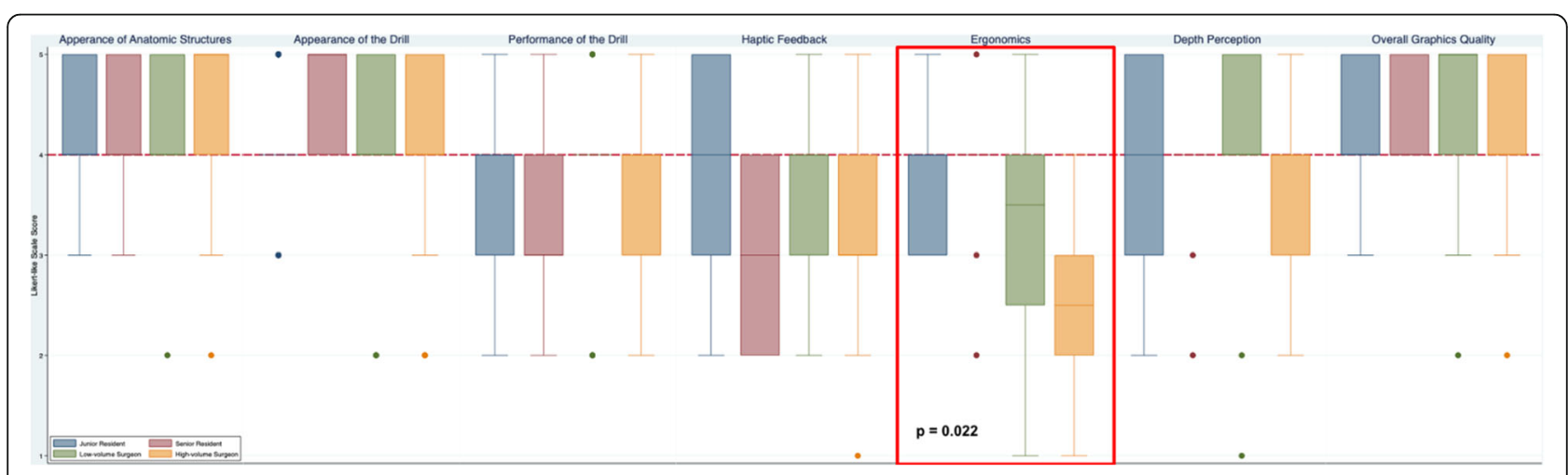

Fig. 2 Face validity (realism) of CardinalSim assessed by otolaryngologists and resident trainees 


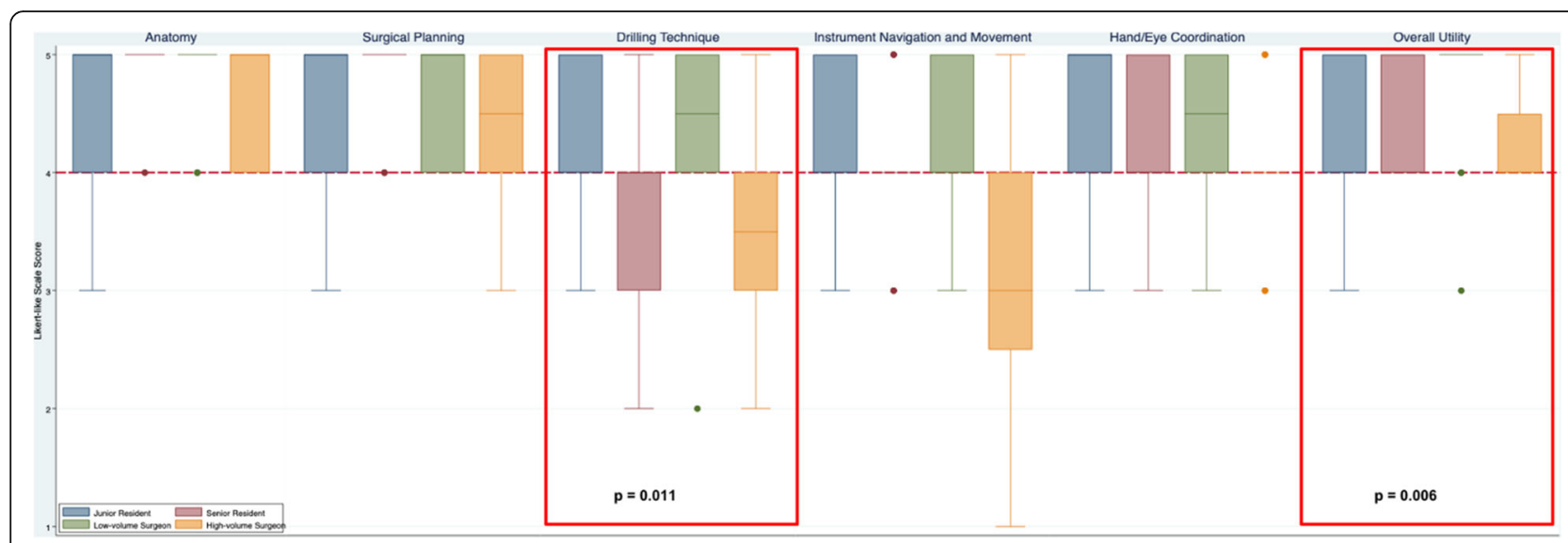

Fig. 3 Content validity of CardinalSim assessed by otolaryngologists and resident trainees 